\title{
Estudios
}

\section{El origen del derecho administrativo}

The origin of administrative law

\author{
Angie Valentina Quintero Cuéllar ${ }^{1}$
}

A Dios, a mis padres, María y Jorge, modelos de vida perennes.

Recepción:11/05/2020 • Aprobación:21/05/2020 • Publicación: 12/08/2020

Para citar este artículo

Quintero Cuéllar, A. V. (2020). El origen del derecho adminis-

trativo. Dos mil tres mil, 22, e233.

https://doi.org/10.35707/dostresmil/22233
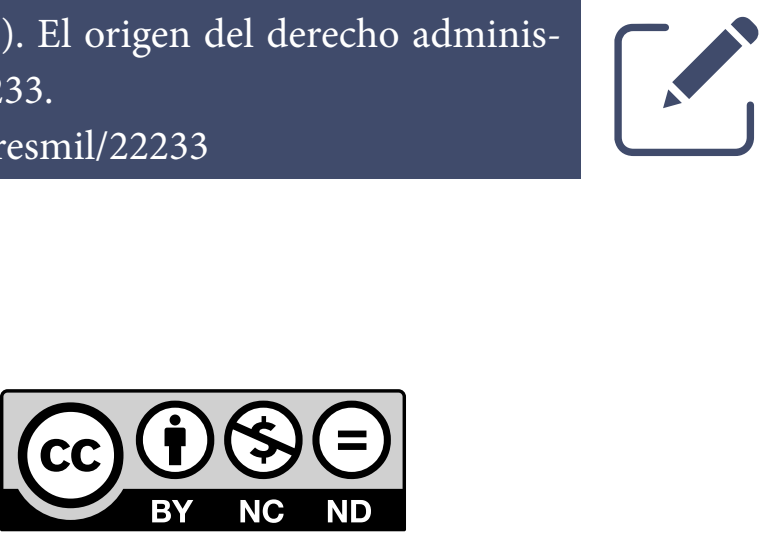

\footnotetext{
${ }^{1}$ Programa de Derecho y Semillero de Investigación de Derecho Administrativo "Jaime Vidal Perdomo" de la Universidad de Ibagué, Colombia. ORCID: 0000-0002-2868-4788. Correo electrónico: angiequintero.99@gmail.com

La autora manifiesta su sentimiento de agradecimiento al profesor Carlos Forero por la revisión de este texto.
} 
Resumen. El texto pretende mostrar a la comunidad académica algunas posturas doctrinarias frente al origen del derecho administrativo. Este artículo se basa en el proceso de recolección y estudio de información cualitativa, consistente en la revisión de libros, artículos de investigación y de reflexión que se han ocupado del tema.

Abstract. The text tries to show the academic community some doctrinal views regarding the origin of administrative law. This article is based on the process of gathering and studying qualitative information which consists of the review of books, research and reflection articles that have addressed the subject.

Palabras claves

Derecho administrativo, administración pública, derecho francés, derecho público.

Key words

Administrative law, public administration, french law, public law. 


\section{Introducción}

El día 25 de marzo de 2020, la dirección del grupo Zoon Politikon, a cargo del doctor Jhon Jairo Uribe Sarmiento, autorizó la constitución del Semillero de Investigación de Derecho Administrativo "Jaime Vidal Perdomo". La constitución del citado Semillero se debió al creciente dinamismo del derecho administrativo, consecuencia de la dependencia que ofrece respecto del fenómeno político-jurídico de intervencionismo del Estado. De ahí la necesidad de estudiar las instituciones del derecho administrativo por parte de los estudiantes, tanto del programa de Derecho como de la Especialización en Derecho Administrativo de la Universidad de Ibagué.

La denominación del Semillero "Jaime Vidal Perdomo", q. e. p. d., se asocia por dos consideraciones. Por un lado, se debe a que Vidal Perdomo fue uno de los brillantes juristas tolimenses (nacido en Icononzo, Tolima); de ahí que las facultades de Derecho a través de sus docentes están llamadas a recordar a sus estudiantes los aportes jurídicos que han realizado los juristas del departamento del Tolima, entre ellos Vidal Perdomo. Por el otro lado, el jurista tolimense fue autor de reconocidas obras de derecho público, entre ellas: Derecho constitucional general e instituciones políticas colombianas (1996), Derecho administrativo (2004), obras consideradas de consulta obligatoria en las aulas del programa de Derecho, así como de posgrados de derecho público (derecho administrativo y constitucional).

En este texto, como resultado de una de las actividades del mencionado Semillero, se mostrarán varias posturas doctrinarias frente al origen del derecho administrativo. Se anticipa señalar que no es tarea fácil identificar el origen del derecho administrativo, por cuanto algunos estudiosos afirman que este proviene del derecho francés; en cambio, otros consideran que no lo es, y señalan que su origen se encuentra en el derecho indiano y en la legislación española.

\section{Método}

Se trata de una investigación con enfoque cualitativo. Por esta razón, este texto explica y profundiza algunas nociones básicas de derecho administrativo, así como identificar su origen. Se elige un diseño secuencial, que comienza con el proceso de recolección y estudio de información cualitativa consistente en la revisión de libros, artículos de investigación y reflexión.

\section{Noción de derecho administrativo}

Del derecho administrativo se han ofrecido tantas nociones como autores se han ocupado del tema. Es pertinente citar varias nociones, para luego concluir que todas ellas vinculan siempre a la noción de administración pública.

Según Zanobini (1954), el derecho administrativo "es aquella parte del derecho público que tiene por objeto la organización, los medios y las formas de la actividad de las administraciones públicas y las consiguientes relaciones jurídicas entre aquellas y otros sujetos" (p. 13). Se considera comprensible esta noción por cuanto incluyó la explicación según la cual es una rama del derecho público. 
García de Enterría (2006) entiende por derecho administrativo como "un derecho de naturaleza estatutaria, en cuanto se dirige a la regulación de las singulares especies de sujetos que se agrupan bajo el nombre de Administraciones Públicas, substrayéndolas del derecho común” (p. 33).

De acuerdo con Posada (1897), este derecho alude al "orden jurídico de la actividad encaminada a procurar la buena disposición de las Administraciones Públicas” (p. 12). Fernández Ruiz, por su parte, explica que el derecho administrativo:

Es el conjunto de normas y principios del derecho público que rigen la estructura, organización, y funcionamientos de las diversas áreas de la administración pública de las relaciones de estas entre sí, así como de sus relaciones con las demás instituciones del Estado y con los particulares. (Fernández Ruiz, 2016, p. 15).

Y, finalmente, Rodríguez advierte que el derecho administrativo es:

El conjunto de principios y reglas jurídicas que tienen por objeto regular la organización de la administración pública y la actividad administrativa de las entidades públicas y de las personas privadas que participan en esa actividad o que son afectadas por ella. (Rodríguez, 2013, p. 19).

Como se evidenció, las nociones citadas frente al derecho administrativo están asociadas con la institución de administración pública, que constituye la temática principal del derecho administrativo. En este texto se comparte la explicación ofrecida por Vidal Perdomo respecto de la noción de administración pública, en los siguientes términos:

Por administración se entiende el conjunto de órganos encargados de cumplir las múltiples intervenciones del Estado moderno y atender los servicios que él presta. Al analizar la definición aparecen un aspecto instrumental y orgánico (por eso se habla de órganos, aunque también de dependencias, entidades, oficinas, agencias, etc.) y otro finalista: el aparato administrativo existe para ejercer la intervención estatal y para atender a la prestación de los servicios a su cargo. (Vidal, 2004, p. 2).

En coincidencia, Rodríguez (2013) señala que la administración pública se estudia en dos sentidos: material y orgánico. El primero alude "a la actividad consistente en manejar una entidad, negocio o empresa" (p. 11). El segundo hace referencia "a los órganos o personas que manejan la entidad, negocio o empresa" (p. 11).

Tal como anota Forero Hernández (2020), es igualmente de derecho administrativo lo relacionado con los controles judiciales (denominados también controles externos) sobre las actuaciones de la administración pública. Enseguida identificaremos el origen del derecho administrativo.

\section{3. ¿Cuál es el origen del derecho administrativo?}

Frente a este interrogante, la doctrina ha dicho mucho. Se resalta que no resulta claro establecer los orígenes del derecho administrativo. 
Rodríguez (2013) explica que "el derecho administrativo como nueva rama jurídica es una concepción francesa, pero es posible encontrar su origen en la época de la Revolución Francesa" (p. 2). Para este autor, el origen del derecho administrativo radica en el derecho francés, específicamente en la Revolución Francesa.

No obstante, tal como lo cita Rodríguez (2013), Georges Vedel advierte que "todo país civilizado poseería un derecho administrativo, puesto que necesariamente posee un conjunto de normas que rigen la acción de la administración" (p. 2). Esto significa que los primeros antecedentes del derecho administrativo se identifican desde los orígenes de las primeras civilizaciones. Explicación que compartimos.

Por su parte, Malagón Pinzón (2004) afirma con sencillez que antes de la Revolución Francesa, en el derecho indiano, por ejemplo, existió un derecho administrativo o al menos un ordenamiento especial para la administración pública, y eso es derecho administrativo y cita un ejemplo: el recurso de agravios que tenía todo súbdito ante la Real Audiencia contra los actos de Gobierno.

Las figuras de recurso de agravios, actos de gobierno, sin duda son de derecho administrativo. Se debe resaltar que el recurso citado se caracteriza como un control judicial (control externo) frente las actuaciones del Estado y eso es derecho administrativo, tal como lo explica Forero Hernández (2020). Con esta aclaración, podemos afirmar que es inviable sostener que el origen del derecho administrativo se encuentra en el derecho francés.

\section{Conclusiones}

Podemos extractar dos conclusiones. La primera indica que no es tarea fácil identificar el origen del derecho administrativo, por cuanto algunos afirman que este radica en el derecho francés (Rodríguez, 2013); otros consideran que es mucho antes de aquel (Malagón, 2004). La segunda conclusión: en este texto acogemos la tesis según la cual su origen se identifica en el derecho indiano a partir de la aplicación de los controles judiciales, que son controles externos (Forero, 2020) sobre las actuaciones de la administración pública y eso es derecho administrativo, y más, cuando se relaciona con la institución administración pública, que es la temática del derecho administrativo (Vidal, 2004).

\section{Referencias}

Fernández Ruiz, J. (2016). Derecho administrativo. México: Instituto de Investigaciones Jurídicas-unAm. Forero Hernández, C. F. (2020). El acto administrativo. Bogotá, Colombia: Ediciones Ibáñez.

García de Enterría, E. (2006). Curso de derecho Administrativo. Madrid, España: Civitas Ediciones S. L.

Malagón Pinzón, M. Á. (2004, enero-junio). La ciencia de la policía y el derecho administrativo. Revista de Estudios Socio Jurídicos, 6 (1): 174-210. Recuperado de https://revistas.urosario.edu.co/index. php/sociojuridicos/article/view/281

Posada, A. (1897). Tratado de derecho administrativo. Madrid, España: Librería de Victoriano Suárez. 
Rodríguez Rodríguez, L. (2013). Derecho administrativo general y colombiano. Bogotá, Colombia: Ediciones Temis.

Vidal Perdomo, J. (2004). Derecho administrativo. Bogotá, Colombia: Ediciones Legis-Universidad del Rosario.

Vidal Perdomo, J. (1996). Derecho constitucional general e instituciones políticas colombianas. Bogotá, Colombia: Ediciones Legis.

Zanobini, G. (1954). Curso de derecho administrativo: Parte general. Buenos Aires, Argentina: Ediciones Arayú. 